\title{
Sepsis and the muscle tissue. A narrative review
}

\author{
ELEOUSA OIKONOMOU, THEMISTOKLIS PARASKEVAS, DIMITRIS VELISSARIS
}

Department of Internal Medicine, University Hospital of Patras, Greece

\begin{abstract}
Sepsis and septic shock are considered major factors in the development of myopathy in critically ill patients, which is correlated with increased morbidity rates and ICU length of stay. The underlying pathophysiology is complex, involving mitochondrial dysfunction, increased protein breakdown and muscle inexcitability. Sepsis induced myopathy is characterized by several electrophysiological and histopathological abnormalities of the muscle, also has clinical consequences such as flaccid weakness and failure to wean from ventilator. In order to reach definite diagnosis, clinical assessment, electrophysiological studies and muscle biopsy must be performed, which can be challenging in daily practice. Ultrasonography as a screening tool can be a promising alternative, especially in the ICU setting. Sepsis and mechanical ventilation have additive effects leading to diaphragm dysfunction thus complicating the patient's clinical course and recovery. Here, we summarize the effects of the septic syndrome on the muscle tissue based on the existing literature.
\end{abstract}

Key words: sepsis, muscle tissue, myopathy, intensive care unit, diaphragm, critical illness.

\section{INTRODUCTION}

Sepsis is a highly complex syndrome and one of the major urgent public health challenges worldwide. It is widely considered to be responsible for the high morbidity and mortality rates observed in critically ill patients within the intensive care unit (ICU). There is an intricate crosstalk between the immune system and the affected tissues, and despite the available therapeutic approaches, the risk of death remains significant. The core problem is identified to be the vast heterogeneity of sepsis combined to the rapidly progressive organ dysfunction. The muscle tissue is affected during the process of the sepsis syndrome and early recognition of muscle abnormalities are important for optimal recovery. A considerable proportion of septic patients during ICU stay will show signs of muscle weakness, which refers to a decrease in muscle strength and causally can be primary or secondary. The occurrence of myopathy in septic patients in the absence of patients' preexisting central nervous system and muscle abnormalities, suggest that sepsis' role on muscle damage during critical illness is detrimental. This is an article referring to the impact of sepsis on the muscle tissue, the related clinical presentation and underlying pathophysiology and the diagnostic approach. An update of the latest existing literature is summarized.

We conducted a search based on three electronic databases (Cochrane Library, Google Scholar, PubMed) using the following keyword combinations: "sepsis", "muscle", "myopathy", "diaphragm". The search was 
conducted in October 2020, and all relevant articles were enrolled in the review. Crossreferencing identified further articles which were added. Only studies who referred to adult patients and have been published after 2000 were included in the review. Only Englishwritten articles were enrolled and experimental studies on animals were exclude

\section{Definitions - History}

Sepsis induced myopathy (SIM) can be defined as a rapidly developed myopathy affecting both respiratory and limb muscles, with characteristic electrophysiological and morphological findings, occurring in septic patients. It typically occurs in the intensive care unit setting, complicating critical illness and resulting in increased long-term morbidity. Sepsis survivors have reduced exercise capacity and muscle strength three months after discharge, and more functional restrictions compared to non-sepsis hospitalizations occur [1]. The pathophysiological effects of sepsis on muscle have not yet been fully clarified but current literature indicates that during sepsis, proinflammatory cytokines and overactive proteolytic enzymes promote rapid protein breakdown and to a lesser extent decreased protein synthesis, subsequently leading to muscle wasting [2].

The clinically detected muscle weakness in ICU patients is attributed to the clinical entity labeled ICU-Acquired Weakness (ICUAW). ICUAW is described as a frequently observed complication in critically ill patients which affects the peripheral muscles as well as the diaphragm and causes failure to wean from mechanical ventilation. In the short term, ICUAW is independently associated with prolonged mechanical ventilation, ICU stay and hospitalization, impeding rehabilitation measures and resulting in increased morbidity and mortality [3]. In the long term, survivors who developed ICUAW, have reduced quality of life and increased mortality 1 year after ICU discharge [4]. Further classification of ICUAW includes Critical Illness Polyneuropathy (CIP), Critical Illness Myopathy (CIM) and their coexistence Critical Illness Polyneuromyopathy (CIPNM) [5]. CIP, first described by Bolton and colleagues in 1986 [6] and CIM, later introduced as a distinct pathological entity, are both frequent and are considered major complications of critical illness and its management. SIM is also situated in the
ICUAW spectrum and sepsis' distinct pathophysiology differentiates it from other ICUAW syndromes $[2,12]$. SIM is a term first coined in 2009 by Callahan and is increasingly used in current literature [2].

Historically, CIM was first described in patients treated with high dose corticosteroids and neuromuscular-blocking agents (NMBAs) for status asthmaticus [7]. These drugs have been broadly used in the ICU setting for a wide range of disorders and are considered to be risk factors for CIM in critically ill patients [8,9], especially when administered in high doses (e.g. usually a total dose of $1000 \mathrm{mg}$ of methylprednisolone or the equivalent) [10]. However, some studies have failed to confirm the above correlation and the occurrence of CIM was not related to NMBAs and corticosteroids administration [11,12]. On the other hand, current literature proposes the severity of illness and the high APACHE III score as risk factors for the development of CIM [11,21] while the results on aminoglycosides are discordant $[11,14]$. Factors that have been identified as independent risk factors in prospective studies are: age, medications such as propofol and vasopressors, preexisting diabetes mellitus, hyperglycemia, high IL-6 plasma levels, abnormal fluctuations of plasma $\mathrm{Ca}^{2+}$ concentration, Gram(-) bacteremia, duration of mechanical ventilation, duration of multiple organ dysfunction, duration of vasopressor and catecholamine support, duration of ICU stay, hyperglycemia, female sex, renal failure and renal replacement therapy, hyperosmolality, parenteral nutrition, low serum albumin, and neurological failure $[8,11,13,14]$. In the setting of critical illness in ICU, two of the greatest pharmacological risk factors for the development of CIM are corticosteroids and non-depolarizing neuromuscular-blocking agents.

A considerable proportion of septic patients during their stay in ICU will show signs of muscle weakness, which refers to a decrease in muscle strength and causally can be primary or secondary. Neuromuscular conditions are the primary cause for weakness in critically ill patients, but only account for less than $0.5 \%$ of all ICU admissions [15]. These include, inter alia, Guillain-Barré Syndrome, myasthenia gravis, amyotrophic lateral sclerosis and multiple sclerosis [16]. In any case, the "failure to wean for the ventilator" is broad and includes several conditions affecting all 
human systems including the muscle. It is worth noting that regardless of the cause of the ICU admission and the current medical condition of each patient, the possibility of pre-existing neuromuscular disorder should be investigated.

\section{Pathophysiology}

Regarding the pathophysiological background of SIM, abundant scientific evidence indicates that sepsis induces a myopathy which involves three main mechanisms: mitochondrial dysfunction leading to bioenergetic failure and oxidative stress, proteolysis mainly related to an activation of the ubiquitin-proteasome pathway, and impairment of muscular membrane excitability [17].

\section{Mitochondrial dysfunction}

Mitochondria represents the primary site for high energy Adenosine Triphosphate (ATP) production through oxidative phosphorylation. Sepsis interferes in this pathway causing significant alterations in cellular homeostasis and metabolism, including decreased ATP production and increased generation of Reacting Oxygen Species [2]. The underlying mitochondrial dysfunction engenders bioenergetic failure and free radical mediated oxidative stress in muscle tissue. This has been the subject of numerous studies focusing on the association between sepsis and mitochondrial function. One of them centralizes in the role of the inducible nitric oxide synthase pathway suggesting that sepsis decreases contractile force through the production of nitric oxide and its toxic secondary products [18]. In humans, dysfunctional mitochondrial respiratory chain can result in metabolic shutdown which incites inadequate production of ATP. Consequently, the energy reserves necessary for cellular functions become insufficient and thus, necrotic, or apoptotic cell death pathways are activated [19]. Worth-mentioning is that the relationship between sepsis-induced changes in mitochondrial function and organ dysfunction is time-dependent in the context of ICU. Severe impairment of the Electron Transport Chain in skeletal muscle biopsies from patients with septic shock has been reported within the first 24 hours after ICU admission [20]. Furthermore, Brealey et al. demonstrated decreased respiratory chain complex I activity combined with elevated nitrate/nitrite ratio and lower ATP levels in skeletal muscle biopsies taken from critically ill patients in septic shock. They also showed a significant correlation between muscle mitochondrial dysfunction and mortality in sepsis [21]. Research targeting the vastus lateralis muscle demonstrates a 50\% reduction of oxidative phosphorylation in sepsis-survivors with protracted critical illness and ICU-acquired weakness [20]. However, a differential pattern of oxidative stress is observed between the peripheral and the respiratory muscles, with levels of oxidized and nitrated proteins rising in the former while remaining stagnant in the latter [22]. An interesting outcome of another study was that sepsis induces the expression of a functional Nitric oxide synthase 2 (NOS2) in human skeletal muscle, along with the local formation of peroxynitrite. These results suggest that NOS2 could be involved in the decreased muscular force of septic patients [18].

To summarize, the scientific community agrees that sepsis is strongly associated with mitochondrial dysfunction, reduced mitochondrial ATP-generating capacity and ATP concentrations, nitric oxide overproduction and antioxidant depletion, leading to organ failure and poor clinical outcome. These data implicate bio-energetic failure as an important pathophysiological mechanism underlying multiorgan dysfunction. The degree of these sepsisinduced mitochondrial abnormalities in the development of the ICU-acquired weakness syndromes is still under investigation.

\section{Protein breakdown}

Sepsis induces an imbalance between protein breakdown and synthesis in the muscle tissue, resulting in net loss of muscle mass, muscle atrophy and disorganization of sarcomeres [14]. The purpose of protein catabolism during infection is to provide the liver enough energy to synthetize acute phase proteins and glutathione [14]. In septic patients, the role of muscle protein breakdown is more prominent than protein synthesis, but the latter also contributes to the metabolic response [23]. Type II muscle fibers are mainly affected and myofibrillar proteins, such as actin and myosin, are the targets of the protein degradation [24]. Four main pathways contribute to the protein degradation in muscle tissue: the ubiquitin-proteasome pathway, the autophagy-lysosome system, calpains and caspase 3 [25].

Increased proteolytic degradation performed by the proteasome pathway has been recognized 
in a plethora of systemic pathologies including sepsis, prior to ubiquitination, calpain and caspase 3 pathways must degrade intact myofibrillar proteins [2]. Significantly higher proteasome activity has been found in respiratory and peripheral muscles of septic patients [23]. In clinical situations, the effects of sepsis-induced proteolysis on the diaphragm may be exacerbated by mechanical ventilation [20]. Additionally, in a study by Klaude [23], lysosomal proteolytic activity (cathepsin B and cathepsin L) was described, but there was no increase in the activity of the other two pathways, caspase 3 and calpain. A soluble molecule, supposedly IL-6, may contribute to the systematic effects of sepsis on muscle as plasma of patients with septic shock has been reported to induce proteolysis in skeletal myotubes [26].

\section{Muscle inexcitability}

Although there has been evidence of muscle inexcitability in CIM for more than two decades [2] and it is considered an important component of sepsis-induced myopathy in animal models [27], no clinical studies on this subject were identified.

\section{Clinical features}

Critical illness myopathy and neuropathy share similar clinical features $[9,12,14]$. They are identified when a patient displays failure to wean from ventilator or flaccid limbs. Deep tendon reflexes are usually decreased, thus CIM was previously called quadriplegic areflexic myopathy. Flaccid weakness is diffuse, symmetrical and affects limb muscles and neck flexors, while facial muscles are mostly spared. Patients with pure myopathy have normal sensation when tested. All references in the current literature report similar clinical features in patients with sepsis-induced myopathy.

\section{Diagnosis of sepsis induced myopathy}

Definite diagnosis of sepsis-induced myopathy requires thorough clinical evaluation, electrophysiological studies and muscle biopsy. Different diagnostic criteria for critical illness myopathy have been proposed by Bolton [9], Latronico [14] and Lacomis [28] but their diagnostic value has not been systematically studied. The criteria apply to critically ill patients presenting with muscle weakness and include specific electrophysiological abnormalities and myopathic findings in biopsy which are analyzed below.
Patients with sepsis or septic shock and emerging weakness who present with symmetric flaccid limb weakness or failure to wean from ventilator require further diagnostic evaluation. First, the existence of neuromuscular weakness before the onset of sepsis must be excluded in order to determine the acute onset of the syndrome. Differential diagnosis of weakness of acute onset includes diseases of the motor neuron, the neuromuscular junction or the muscle, with Guillain - Barré Syndrome and rhabdomyolysis being the most prominent in critical ill population. Cardiovascular and pulmonary diseases with the related pathologies are common etiologies of failure to wean from a ventilator and therefore must be excluded. In the absence of other possible diagnoses, critical illness polyneuropathy and/or myopathy must be considered. Muscle biopsy may be crucial for a definite diagnosis but is often difficult to perform in everyday practice.

\section{Clinical assessment}

Continuous clinical assessment including the muscles is part of the clinicians' daily activity. In the ICU environment its importance is sometimes underestimated as patients are often under sedative medication. The Medical Research Council (MRC) scale and handgrip strength dynamometry can be used to clinically assess a patient's strength. In the MRC scale six bilateral muscle groups are evaluated and a score from 0 to 5 is assigned to each movement. Each individual score is added, and the final score is calculated. Results range from 0 (complete tetraparesis) to 60 (normal strength) and patients with scores lower than 48 are considered to have clinically significant weakness. The reliability and validity of the MRC scale has been validated [29] but is limited by its inability to assess sedated and uncooperative patients. Instead, nonvolitional methods such as direct muscle stimulation and muscle biopsy can be used in these patients. Handgrip dynamometry is another volitional method that shares the same limitation, but it can substitute MRC scale as a simpler and quicker method to assess weakness. In a study of critical ill patients, the majority of which suffered from sepsis syndromes, handgrip dynamometry was able to identify patients with poor prognosis [30]. 


\section{Electrophysiologic assessment}

Electrophysiological findings consistent with the diagnosis of myopathy are: 1) CMAP (Compound Muscle Action Potential) amplitudes less than $80 \%$ of the lower limit of normal in two or more nerves without conduction block, 2) Sensory nerve action potential amplitudes more than $80 \%$ of the lower limit of normal, 3) Needle electromyography with short duration, lowamplitude motor unit potentials with early or normal full recruitment, with or without fibrillation potentials in conscious and collaborative patients, or increased CMAP duration or reduced muscle membrane excitability on direct muscle stimulation in non-collaborative patients, 4) Absence of a decremental response on repetitive nerve stimulation [14]. According to Latronico et al., possible diagnosis of myopathy is established if all electrophysiological criteria are met [14]. Reduced CMAP in single nerve conduction studies of the sural or peroneal nerve may suffice [33]. Reduced SNAP (Sensory Nerve Action Potential) or sensory deficits may be present in combined polyneuropathymyopathy syndrome.

The presence of clinical weakness, biopsy and electrophysiological changes consistent with myopathy establish a definite diagnosis [14]. Based on this, definite diagnosis cannot be made in sedated patients, which is the case for many ICU septic-patients in the early course of the disease. Early diagnosis can identify patients with poor prognosis and perhaps modify their treatment plan, provided that more studies are conducted on this subject in the future.

\section{Electrophysiological studies}

Among septic patients, combined neuropathy-myopathy is the most frequent clinical scenario [32]. In a study of patients with severe sepsis, 63\% had Nerve Conduction Studies (NCS) abnormalities and most of them had both evidence of myopathy and neuropathy [32]. Using direct muscle stimulation, Lefaucheur et al reported predominance of myopathies in weak patients with sepsis in the ICU [33]. Combined Direct Muscle Stimulation (DMS) and NCS can adequately determine and differentiate the two syndromes [33]. Technical factors such as peripheral edema, limited access to sites of stimulation and difficulty in maintaining limb temperature may influence the results of nerve conduction studies. Measuring velocity recovery cycles can be used to monitor patients with myopathy [34]. Measurement of CMAP and SNAP of the peroneal and sural nerves can reliably diagnose neuromuscular abnormalities in septic patients [31]. Single nerve conduction studies were problematic when used on patients with preexisting polyneuropathies and according to the authors would likely not be suitable for patients with chronic neuropathies and other chronic conditions associated with them (e.g. diabetes mellitus) [32]. DMS is a non-volitional method used to assess muscle function and was consistent with NCS in a study by Crone [35].

\section{Muscle biopsy}

Muscle biopsy is considered the most accurate method to diagnose myopathic changes but should be combined with electrophysiological studies [36]. The results of these two are not always in agreement. Myopathic changes in biopsy include a) a general decrease in myofibrillar protein content; b) specific but highly variable partial or complete loss of myosin and myosin-associated proteins; c) very low thick-filament/thinfilament protein ratios; d) absence of myosin mRNA; and e) a decreased muscle cell forcegenerating capacity in the acute phase of myopathy [37]. These findings were reported by Larsson et al. [37] but it should be noted that patients in this study were treated with high doses of corticosteroids and NMBDs. Both treatments have been considered as the main risk factors for CIPNM syndromes, but these views have been challenged [12]. In septic patients myopathy can occur in the absence of corticosteroids and NMBDs [38]. According to biopsy findings, critical illness myopathy has been categorized as a) necrotizing myopathy, b) cachectic myopathy, c) thick filament myopathy [14], with varying degrees of prognosis, but these subtypes have not been exclusively studied within the context of sepsis. Kerbaul et al concluded that the combination of electromyography (EMG) and biopsy can distinguish the type of the weakness and evaluate potential functional outcomes [38].

\section{Muscle ultrasonography}

Ultrasonography (U/S) can be a useful tool to measure muscle thickness in the setting of ICU. Muscle wasting in sepsis results in a loss 
of approximately $10 \%$ of muscle thickness during ICU stay [39], with a daily reduction of the rectus femoris cross sectional area of $1.45 \%$ [40]. Muscle wasting occurs rapidly in the early stages of the disease and is more pronounced in patients with multiple organ failure [41]. Decline in muscle thickness is associated with clinical weakness and can be a predictive factor of mortality if measured between day 1 and 3 of ICU stay (sensitivity 0.81 , specificity 0.81 , CI 0.81 ) [39]. Reduced rectus femoris cross sectional area has been associated with handgrip strength in septic patients [40]. Therefore, ultrasonography can be used to identify patients with poor prognosis. Skeletal muscle wasting has been associated with findings from U/S and muscle biopsy and decreased protein to DNA ratio [41]. In addition to muscle thickness, alterations in muscle echotextures in early stages of sepsis have been reported [42], but these changes were not correlated significantly with function. Another study outlines that muscle necrosis can be predicted by increased muscle echogenicity [43]. Fascial inflammation accompanying muscle necrosis was also reported in this study and was detectable with ultrasonography. Hence, U/S could be useful as a screening tool before subjecting patients to NCS and muscle biopsy.

\section{Diaphragm dysfunction}

Diaphragm is the dome-shaped muscular and fibrous membrane that separates the thoracic and abdominal cavities. During the breathing process, diaphragm muscle contraction coaxes the enlargement of the thoracic cavity as well as the reduction of the intrathoracic pressure resulting in the filling of the alveoli with air. It is the main inspiratory muscle, thus its dysfunction - defined as a reduced capacity of the diaphragm to produce a negative intrathoracic pressure in response to phrenic stimulation [44] - can lead to significant adverse clinical consequences.

Diaphragm dysfunction in the ICU setting is frequent and can occur through different mechanisms including sepsis, CIPNM, pharmacological exposure, metabolic derangements, and excessive muscle loading and unloading. Regarding sepsis, it is considered as a major independent risk factor for diaphragm dysfunction on ICU admission [44] and can provoke failure to wean from the ventilator along with prolonged ventilation [45].
Sepsis and mechanical ventilation have been described as the "perfect storm", due to their additive effects on the patient's health, with evidence suggesting that mechanical ventilation impedes diaphragmatic recovery in septic patients by increasing oxidative stress and causing mitochondrial dysfunction [46]. This theory is also supported by a recent study which associated sepsis with earlier and more severe diaphragm dysfunction in mechanically ventilated patients [47].

As diaphragm dysfunction has become a subject of major concern in ICU patients and sepsis remains a major health problem in these patients worldwide, many studies in recent years have focused on this correlation. One of them, mainly consisting of septic patients (61\%), has proved that a reduced capacity to produce inspiratory pressure is often present on ICU admission and it is associated with sepsis as well as poor clinical outcome. In addition, diaphragm dysfunction, considered to be an example of sepsis-related organ failure, was associated with higher mortality but not prolonged mechanical ventilation or ICU stays [44]. Contrariwise, a study by Lu et al., in a septic population, found statistically significant increased ventilation time and ICU stays in patients diagnosed with diaphragm dysfunction, but no increase in the mortality [48]. It must be noted that the prevalence of diaphragm dysfunction in this population was $41 \%$, in contrast to $64 \%$ of the aforementioned study. Due to the conflicting results, more research is warranted to clarify the effects of the diaphragm dysfunction in ICU septic patients.

Critically ill patients are prone to dysfunction of both respiratory and peripheral muscles, and patients with sepsis may be particularly at risk of presenting muscle wasting and weakness regarding both muscle groups. Despite the growing body of relevant literature, the question of whether limb muscles or diaphragm is more intensely affected during sepsis remains controversial. On the topic of the coexistence of peripheral weakness and diaphragm dysfunction, evidence show that they are two different processes. Recent data described a preferential loss of diaphragm volume compared to psoas, plus an association of this diaphragm atrophy with a lower contractile force in septic patients [49]. However, studying sepsis survivors, Baldwin et al. presented greater deficits in peripheral 
muscle strength and size compared to the diaphragm, as patients' diaphragm thickness did not differ from the control group [50]. As reported by Vivier et al., the occurrence of diaphragm and pectoral atrophy was $48 \%$ and $29 \%$ respectively, without a significant correlation between the two [51]. Surprisingly in another study, diaphragm dysfunction did not impact mechanical ventilation which was attributed to small sample size and competing pathologic processes [52]. On the other hand, a study with a much greater sepsis population (89\% septic patients), showed associated diaphragm dysfunction with longer mechanical ventilation and increased risk of related complications including reintubation, tracheostomy or death [51].

It should be noted that diaphragm atrophy and diaphragm contractile activity are not synonymous. Lu et al. demonstrated more intense diaphragm contractile activity impairment in septic patients but not increased atrophy when compared to non-septic critically ill patients in the early course of the disease [47]. Likewise, sepsis survivors present with persistent respiratory muscle weakness without remarkable atrophy [50].

Assessment of diaphragm function can be achieved through volitional (pressure generated during maximal inspiratory efforts) and non-volitional methods (stimulation of the phrenic nerve). Ultrasound can be used to measure the diaphragm's thickness, its thickening fraction during contraction and its maximal excursion. All the studies we reviewed were limited by the fact that biopsy was not performed and thus there was no separation between myopathic or neuropathic origins of diaphragm dysfunction.

\section{CONCLUSIONS AND TAKE-HOME MESSAGES}

- $\quad$ The muscle tissue is affected during the process of sepsis syndrome as part of its underlying complex pathophysiology.

- Sepsis induced myopathy can complicate critical illness by affecting both respiratory and limb muscles and lead to increased long-term morbidity.

- Intensive evaluation of the muscle tissue based on clinical assessment, electrophysiological studies and biopsy should be considered especially in the prolonged illness and the ICU setting.

- Ultrasonography is an emerging screening tool that can be used to measure significant parameters of muscle function at patient's bedside, before subjecting patients to nerve conduction studies and muscle biopsy.

- Diaphragm dysfunction strongly affects patients' outcome in the ICU thus additional research on the sepsis-mediated effects on diaphragm must be conducted in order to unravel its pathophysiology and relation to peripheral myopathy

Sepsisul și șocul septic sunt considerați factori majori de risc pentru dezvoltarea miopatiei la pacienții în stare gravă, ceea ce se corelează cu o morbiditate crescută și cu prelungirea internării în secțiile ATI. Fiziopatologia este complexă, cuprinzând disfuncția mitocondrială, catabolimsul proteic și inexcitabilitatea musculară. Miopatia indusă de sepsis este caracterizată prin modificări histopatologice și electrofiziologice ale mușchiului, ceea ce se asociază cu slăbiciune flască și o independență tardivă de ventilator. Pentru a putea pune diagnosticul trebuie realizate evaluări clinice, electrofiziologice și biopsie musculară. Ecografia este o alternativă promițătoare de screening, mai ales în secțiile de ATI. Sepsisul și ventilația mecanică prezintă efecte aditive ducând la disfuncții ale diafragmului și complicând recuperarea și evoluția clinică. În această lucrare sunt sumarizate efectele șocului septic asupra țesutului muscular din datele existente în literatura de specialitate. 
Correspondence to: Dimitris Velissaris MD, PhD Associate Professor at University of Patras, Greece, e-mail: dvelissaris@upatras.gr, mobile: 0030 6974909988, tel. work: 00302610 999583,zip code: 26504

Author's contribution: EO and TP did literature search and wrote the manuscript. EO and TP contributed equally in the manuscript. DV wrote the manuscript and supervised the study.

Financial support and sponsorship: Nil

Conflict of interest disclosure: The authors declare that there are no conflicts of interest.

\section{REFERENCES}

1. BORGES RC, CARVALHO CRF, COLOMBO AS, DA SILVA BORGES MP, SORIANO FG. Physical activity, muscle strength, and exercise capacity 3 months after severe sepsis and septic shock. Intensive Care Med. 2015;41(8):1433-1444.

2. CALLAHAN LA, SUPINSKI GS. Sepsis-induced myopathy. Crit Care Med. 2009;37(10 Suppl):S354-S367.

3. LATRONICO N, GOSSELINK R. A guided approach to diagnose severe muscle weakness in the intensive care unit. Rev Bras Ter intensiva. 2015;27(3):199-201.

4. HERMANS G, VAN MECHELEN H, CLERCKX B, et al. Acute outcomes and 1-year mortality of intensive care unitacquired weakness. A cohort study and propensity-matched analysis. Am J Respir Crit Care Med. 2014;190(4):410-420.

5. SHEPHERD S, BATRA A, LERNER DP. Review of Critical Illness Myopathy and Neuropathy. The Neurohospitalist. 2017;7(1):41-48.

6. BOLTON CF, LAVERTY DA, BROWN JD, WITT NJ, HAHN AF, SIBBALD WJ. Critically ill polyneuropathy: electrophysiological studies and differentiation from Guillain-Barré syndrome. J Neurol Neurosurg Psychiatry. 1986;49(5):563-573.

7. MACFARLANE IA, ROSENTHAL FD. Severe myopathy after status asthmaticus. Lancet (London, England). 1977;2(8038):615

8. De Jonghe B, Lacherade J-C, Sharshar T, Outin H. Intensive care unit-acquired weakness: risk factors and prevention. Crit Care Med. 2009;37(10 Suppl):S309-15.

9. BOLTON CF. Neuromuscular manifestations of critical illness. Muscle Nerve. 2005;32(2):140-163.

10. BIRD SJ. Diagnosis and management of critical illness polyneuropathy and critical illness myopathy. Curr Treat Options Neurol. 2007;9(2):85-92.

11. WEBER-CARSTENS S, DEJA M, KOCH S, et al. Risk factors in critical illness myopathy during the early course of critical illness: a prospective observational study. Crit Care. 2010;14(3):R119.

12. FRIEDRICH O, REID MB, VAN DEN BERGHE G, et al. The Sick and the Weak: Neuropathies/Myopathies in the Critically Ill. Physiol Rev. 2015;95(3):1025-1109.

13. QIU Y, JIANG L, XI X. [Early incidence and prognosis of ICU-acquired weakness in mechanical ventilation patients]. Zhonghua Wei Zhong Bing Ji Jiu Yi Xue. 2019;31(7):821-826.

14. LATRONICO N, BOLTON CF. Critical illness polyneuropathy and myopathy: a major cause of muscle weakness and paralysis. Lancet Neurol. 2011;10(10):931-941.

15. VANHOREBEEK I, LATRONICO N, VAN DEN BERGHE G. ICU-acquired weakness. Intensive Care Med. 2020;46(4):637-653.

16. DAMIAN MS, WIJDICKS EFM. The clinical management of neuromuscular disorders in intensive care. Neuromuscul Disord. 2019;29(2):85-96.

17. BOUGLÉ A, ROCHETEAU P, SHARSHAR T, CHRÉTIEN F. Muscle regeneration after sepsis. Crit Care. 2016;20(1):131.

18. LANONE S, MEBAZAA A, HEYMES C, et al. Muscular contractile failure in septic patients: role of the inducible nitric oxide synthase pathway. Am J Respir Crit Care Med. 2000;162(6):2308-2315.

19. HOTCHKISS RS, STRASSER A, MCDUNN JE, SWANSON PE. Cell death. N Engl J Med. 2009;361(16):1570-1583.

20. MAESTRAGGI Q, LEBAS B, CLERE-JEHL R, et al. Skeletal Muscle and Lymphocyte Mitochondrial Dysfunctions in Septic Shock Trigger ICU-Acquired Weakness and Sepsis-Induced Immunoparalysis. Biomed Res Int. 2017;2017:7897325.

21. BREALEY D, BRAND M, HARGREAVES I, et al. Association between mitochondrial dysfunction and severity and outcome of septic shock. Lancet (London, England). 2002;360(9328):219-223.

22. PASCUAL-GUARDIA S, ÁRBOL F, SÁNCHEZ E, et al. [Inflammation and oxidative stress in respiratory and limb muscles of patients with severe sepsis]. Med Clin (Barc). 2013;141(5):194-200.

23. KLAUDE M, MORI M, TJÄDER I, GUSTAFSSON T, WERNERMAN J, ROOYACKERS O. Protein metabolism and gene expression in skeletal muscle of critically ill patients with sepsis. Clin Sci (Lond).

24. LAGHI F, TOBIN MJ. Disorders of the respiratory muscles. Am J Respir Crit Care Med. 2003;168(1):10-48.

25. JAGOE RT, GOLDBERG AL. What do we really know about the ubiquitin-proteasome pathway in muscle atrophy? Curr Opin Clin Nutr Metab Care. 2001;4(3).

26. VAN HEES HWH, SCHELLEKENS W-JM, LINKELS M, et al. Plasma from septic shock patients induces loss of muscle protein. Crit Care. 2011;15(5):R233-R233.

27. FRIEDRICH O. Critical illness myopathy: sepsis-mediated failure of the peripheral nervous system. Eur J Anaesthesiol | EJA. 2008;25. 
28. LACOMIS D. Neuromuscular disorders in critically ill patients: review and update. J Clin Neuromuscul Dis. 2011;12(4):197-218.

29. PATERNOSTRO-SLUGA T, GRIM-STIEGER M, POSCH M, et al. Reliability and validity of the Medical Research Council (MRC) scale and a modified scale for testing muscle strength in patients with radial palsy. J Rehabil Med. 2008;40(8):665-671.

30. ALI NA, O'BRIEN JMJ, HOFFMANN SP, et al. Acquired weakness, handgrip strength, and mortality in critically ill patients. Am J Respir Crit Care Med. 2008;178(3):261-268.

31. LATRONICO N, NATTINO G, GUARNERI B, et al. Validation of the peroneal nerve test to diagnose critical illness polyneuropathy and myopathy in the intensive care unit: the multicentre Italian CRIMYNE-2 diagnostic accuracy study. F1000Research. 2014;3:127.

32. KHAN J, HARRISON TB, RICH MM, MOSS M. Early development of critical illness myopathy and neuropathy in patients with severe sepsis. Neurology. 2006;67(8):1421-1425.

33. LEFAUCHEUR J-P, NORDINE T, RODRIGUEZ P, BROCHARD L. Origin of ICU acquired paresis determined by direct muscle stimulation. J Neurol Neurosurg Psychiatry. 2006;77(4):500-506.

34. Z'GRAGGEN WJ, BRANDER L, TUCHSCHERER D, SCHEIDEGGER O, TAKALA J, BOSTOCK H. Muscle membrane dysfunction in critical illness myopathy assessed by velocity recovery cycles. Clin Neurophysiol Off J Int Fed Clin Neurophysiol. 2011;122(4):834-841.

35. CRONE C. Tetraparetic critically ill patients show electrophysiological signs of myopathy. Muscle Nerve. 2017;56(3):433-440.

36. RAGHIG H, BRYAN YOUNG G, HAMMOND R, NICOLLE M. A Comparison of EMG and Muscle Biopsy in ICU Weakness. Neurocrit Care. 2010;13(3):326-330.

37. LARSSON L, LI X, EDSTRÖM L, et al. Acute quadriplegia and loss of muscle myosin in patients treated with nondepolarizing neuromuscular blocking agents and corticosteroids: mechanisms at the cellular and molecular levels. Crit Care Med. 2000;28(1):34-45.

38. KERBAUL F, BROUSSE M, COLLART F, et al. Combination of histopathological and electromyographic patterns can help to evaluate functional outcome of critical ill patients with neuromuscular weakness syndromes. Crit Care. 2004;8(6):R358-R366.

39. HADDA V, KUMAR R, KHILNANI GC, et al. Trends of loss of peripheral muscle thickness on ultrasonography and its relationship with outcomes among patients with sepsis. J intensive care. 2018;6:81.

40. BORGES RC, SORIANO FG. Association Between Muscle Wasting and Muscle Strength in Patients Who Developed Severe Sepsis and Septic Shock. Shock. 2019;51(3):312-320.

41. PUTHUCHEARY ZA, RAWAL J, MCPHAIL M, et al. Acute Skeletal Muscle Wasting in Critical Illness. JAMA. 2013;310(15):1591-1600.

42. GRIMM A, TESCHNER U, PORZELIUS C, et al. Muscle ultrasound for early assessment of critical illness neuromyopathy in severe sepsis. Crit Care. 2013;17(5):R227-R227.

43. PUTHUCHEARY ZA, PHADKE R, RAWAL J, et al. Qualitative Ultrasound in Acute Critical Illness Muscle Wasting. Crit Care Med. 2015;43(8):1603-1611.

44. DEMOULE A, JUNG B, PRODANOVIC H, et al. Diaphragm dysfunction on admission to the intensive care unit. Prevalence, risk factors, and prognostic impact-a prospective study. Am J Respir Crit Care Med. 2013;188(2):213-219.

45. SCHREIBER A, BERTONI M, GOLIGHER EC. Avoiding Respiratory and Peripheral Muscle Injury During Mechanical Ventilation: Diaphragm-Protective Ventilation and Early Mobilization. Crit Care Clin. 2018;34(3):357-381.

46. PETROF BJ. Diaphragmatic dysfunction in the intensive care unit: caught in the cross-fire between sepsis and mechanical ventilation. Crit Care. 2013;17(4):R181-R181.

47. LU Z, GE H, XU L, GUO F, ZHANG G, WU Y. Alterations in diaphragmatic function assessed by ultrasonography in mechanically ventilated patients with sepsis. J Clin Ultrasound. 2019;47(4):206-211.

48. LU ZH, GUO F, ZHANG G, GE HQ, XU LL, CHEN YL. [A clinical study of diaphragmatic dysfunction in subjects with mechanical ventilation in sepsis]. Zhonghua jie he he hu xi za zhi $=$ Zhonghua jiehe he huxi zazhi $=$ Chinese $\mathrm{J}$ Tuberc Respir Dis. 2018;41(9):696-700.

49. JUNG B, NOUGARET S, CONSEIL M, et al. Sepsis Is Associated with a Preferential Diaphragmatic Atrophy: A Critically Ill Patient Study Using Tridimensional Computed Tomography. Anesthesiology. 2014;120(5):1182-1191.

50. BALDWIN CE, BERSTEN AD. Alterations in Respiratory and Limb Muscle Strength and Size in Patients With Sepsis Who Are Mechanically Ventilated. Phys Ther. 2014;94(1):68-82.

51. VIVIER E, ROUSSEY A, DOROSZEWSKI F, et al. Atrophy of Diaphragm and Pectoral Muscles in Critically Ill Patients. Anesthesiology. 2019;131(3):569-579.

52. GOLIGHER EC, DRES M, FAN E, et al. Mechanical Ventilation-induced Diaphragm Atrophy Strongly Impacts Clinical Outcomes. Am J Respir Crit Care Med. 2018;197(2):204-213.

Received $5^{\text {th }}$ December 2020 